\title{
Eco-efficiency and effectiveness evaluation toward sustainable urban development in China: a super-efficiency SBM-DEA with undesirable outputs
}

\author{
Liang-jun Long ${ }^{1}$
}

Received: 1 February 2020 / Accepted: 7 February 2021 / Published online: 20 February 2021

(c) The Author(s) 2021

\begin{abstract}
Eco-efficiency, especially the total-factor eco-efficiency, measured by DEA models considering undesirable outputs, has been a popular instrument to evaluate sustainable development in recent years. However, sustainable development pursues not only high ecoefficiency which ensures that the utilization of natural resource and environment is in a sustainable way, but also good effectiveness which ensures that the development is in the right direction. In this paper, firstly, the efficiency of sustainable urban development is measured, i.e., measuring the eco-efficiency of 35 major cities in China during the period of 2011-2015 based on a super-efficiency SBM-DEA model with undesirable outputs and the Malmquist-Luenberger index is used to explore the dynamic change of eco-efficiency. Secondly, the effectiveness of urban development is measured by overall well-being including urban HDI and life satisfaction. Thirdly, a comprehensive analysis based on efficiency and effectiveness is conducted to evaluate sustainable urban development. The results indicate that: (1) the overall efficiency of 35 major cities in China as a whole is at a low level during the 12th five-year plan period, and the improvement of total-factor ecological productivity is mainly enhanced by technological progress. (2) With regarding to the effectiveness of urban development, Hangzhou, Jinan, Ningbo, Xiamen and Qingdao rank top five, while the cities with a high level of urban HDI like Guangzhou, Changsha and Beijing only rank in the middle due to a relatively low level of life satisfaction. (3) Based on efficiency and effectiveness, most of the cities perform with a low-level efficiency or poor effectiveness, only four cities including Qingdao, Changchun, Ningbo and Tianjin perform with a relatively high efficiency and good effectiveness. Finally, some implications and policy suggestions are proposed based on the above findings.
\end{abstract}

Keywords Sustainable urban development · Efficiency and effectiveness · Total-factor eco-efficiency $\cdot$ Human well-being $\cdot$ Life satisfaction · Super-efficiency SBM-DEA model · Malmquist-Luenberger index

Liang-jun Long

alan_long888@163.com

1 Institute of Systems Engineering, Academy of Military Sciences PLA, Beijing 100141, China 


\section{Introduction}

China's urbanization and high-tech development in the United States are two key factors affecting the twenty-first century, which was claimed by Nobel Laureate Joseph Stiglitz in 2005 (Bloomberg News 2012). In 2019, China's urbanization rate has reached $60.60 \%$ (NBSC 2020), which means almost 850 million people have been living in the cities. Moreover, the rapid development of urbanization and industrialization has been the core driving force that making China becomes the second largest economy in the world (Zhang et al. 2019). However, the economy miracle is achieved at a huge cost of resource consumption and environmental pollution, and the constraints of resource and environment have been a big threaten to our urban ecosystem. Thus, sustainable urban development has become a major concern for the Chinese government as well as the global institutions and organizations.

The concept of sustainable development was formally proposed in 1987, defined as a development pattern that meets the needs of the prevention without compromising the ability of future generations to meet their own needs (Brundtland and Khalid 1987). However, sustainable development has struggled to develop from a concept into practice. In most cases, sustainable development emphasizes the reduction of natural and environmental stress, or focuses on human well-being and regional equity. The ultimate goal of sustainable development is to improve the level of human well-being (Dresner 2012). Urbanization is an inevitable trend and the dominant form of global social and economic development (Yang 2012; Boone and Fragkias 2013); therefore, urban sustainable development is the practice of sustainable development at a local scale (Opschoor 2011).

Over the past decades, a large number of studies have focused on evaluating urban sustainable development (Singh et al. 2009). One of the popular methods to evaluate sustainable development of a country is eco-efficiency, the concept of eco-efficiency was initially proposed by Schaltegger and Sturm (1990), which is usually calculated by the ratio of gross domestic product (GDP) to environmental impacts. Various efforts have been made to study urban sustainability at the urban, regional, national and international level (Moussiopoulos et al. 2010; Shen et al. 2011; Wursthorn et al. 2011; Yin et al. 2014). In order to conduct a comprehensive evaluation on sustainable development, the method of index system was widely adopted by international and regional organizations international and regional organizations at initial stage, such as driving force-state-response (DSR), pressstate-response (PSR), environmental sustainability index (ESI), environmental performance Index (EPI), city development index (CDI), etc. (Böhringer and Jochem 2007).

However, these index systems are constructed under the premise that all indicators from social, economic and ecological dimensions can be added into an overall index in a linear way, then ranked based on the overall scores, which means the indicators can be substituted, and the development the of city or country will be regarded as more sustainable only if the overall score is high. In this way, the total score will be at a high level if the GDP of a city or country is big enough, even if the score in environmental dimension is not high, since GDP is achieved at the cost of environmental degradation. Other popular indexes like ecological footprint (EF) (Wackernagel and Rees 1996), human development index (HDI) (Shaw 1991) are evaluated in only one aspect of sustainable development, which easily leads to an incomplete evaluation.

Therefore, some scholars proposed the ratio method considering both human wellbeing and environmental impacts. For instance, the Happy Planet Index (HPI) (Marks et al. 2006) is measured by the ratio of the average happy life years (HLY) and ecological 
footprint (EF) per capita at the national level. Happy Planet Index (HPI) $=$ HLY/EF (Marks et al. 2006). Similarly, the index of eco-efficiency expressed by GDP/EF (Lin et al. 2010; Yue et al. 2017) and HDI/EF (Yan et al. 2018) was widely used as an instrument for measuring sustainability. However, the indexes are calculated as a ratio for the convenience of comparison, but this method fails to explore the room for improvement of each indicators, as the amount of energy-saving and emission reduction is very important to promote sustainable development.

To avoid these problems, some scholars proposed a non-parametric method to measure the eco-efficiency from an input-output perspective. As a typical representative, data envelopment analysis (DEA) method was first proposed by Charnes et al. (1978), and it has been widely used in many fields at different levels. And different DEA models have been developed for measuring efficiency (Cook and Seiford 2009). Mardani et al. (2017) conducted a study of literature review on 144 papers on DEA published in 45 high-ranking journals from 2006 to 2015, and found that DEA is most commonly used for the measurement and evaluation of environmental or ecological efficiency. The effectiveness means the quality of sustainable development of a country or city that providing with a high level of well-being for the local people. Although the eco-efficiency is an important part that sustainable development demands the good effectiveness that promoting human well-being is the ultimate goal of sustainable development (Ikeda and Managi 2019). Thus, efficiency and effectiveness are equally important, the development will be unsustainable in the near future without considering the efficiency of ecological input, and the development will be off-track and fall into an efficiency trap without considering the effectiveness.

To fill the gap of above studies, it is necessary to conduct a comprehensive analysis on sustainable urban development. In this paper, firstly, the efficiency of sustainable urban development is measured, i.e., measuring the eco-efficiency of 35 major cities in China during the period of 2011-2015 based on a super-efficiency SBM-DEA model in which capital, labor, land, energy and water are adopted as inputs, and the GDP is treated as a desirable output, while $\mathrm{SO}_{2}$ emission is treated as an undesirable output. Then, a comprehensive comparison and analysis is conducted from the perspective of efficiency and effectiveness, where the efficiency is measured by eco-efficiency and the effectiveness is measured by overall human well-being including the objective and subjective aspects.

The rest of this paper is structured as follows: Sect. 2 introduces the construction of a super-efficiency SBM-DEA model considering undesirable output, which is used to measure eco-efficiency. Section 2 also introduces the Malmquist-Luenberger index and the overall human well-being index. In Sect. 3, this study first describes the measurement and evaluation of eco-efficiencies of 35 major cities in China; in addition, a dynamic analysis on total-factor eco-efficiency is conducted by Malmquist-Luenberger index, then based on efficiency and effectiveness, carries out a comprehensive analysis on sustainable urban development of 35 major cities in China. In Sect. 4, conclusions and policy implications are proposed based on the empirical results.

\section{Methodology and data}

In this section, a super-efficiency SBM-DEA model with considering undesirable output is proposed for measuring the eco-efficiency of 35 major cities in China. On this basis, the Malmquist-Luenberger index is proposed to analyze the dynamic changes of total factor 
productivity in different years. Thus, the methodology and data will be introduced in this section as below.

\subsection{Super-efficiency SBM-DEA model}

Traditional DEA models, such as the CCR and BBC models, initially proposed by Charnes et al. (1978) and Banker et al. (1984), both are radial projection constructs (Cook and Seiford 2009), which fails to take the slack variable problem into consideration. Moreover, the efficiency score of the DMU is defined as 1 when the DMU is on the frontier, so it is difficult to rank DMUs when more than one DMU is judged as efficient. Traditional DEA models assume that the more outputs, the higher efficiency the DMU. However, some environmental pollutants such as $\mathrm{CO}_{2}$ or $\mathrm{SO}_{2}$ emissions called undesirable outputs are inevitably produced simultaneously with desirable outputs such as GDP during the whole production process, while the essence of eco-efficiency is expected to maximize the GDP and minimize the pollutions. Thus, the assumption of traditional DEA models is not suitable for the treatment of undesirable outputs (Wang and Yang 2019).

To solve the above problems, Tone (2001) proposed a slack-based measure (SBM) of the DEA model to avoid the slack variable problem. On this basis, Tone (2002) further developed a super-efficiency SBM-DEA model that allows the efficiency score to be higher than 1 and can easily rank efficient DMUs. In this case, Cooper et al. (2006) proposed a SBM-DEA model considering undesirable outputs. Based on Tone (2002) and Cooper et al. (2006), the modified super-efficiency SBM-DEA model considering undesirable outputs under the assumption of constant returns to scale (CRS) is introduced as shown in Eq. (1).

$$
\begin{aligned}
\rho_{s e}= & \min \frac{\frac{1}{m} \sum_{n=1}^{m} \frac{\bar{x}_{i}}{x_{i 0}}}{\frac{1}{s_{1}+s_{2}}\left(\sum_{r=1}^{s_{1}} \frac{\bar{y}_{r}^{g}}{y_{r 0}^{g}}+\sum_{r=1}^{s_{2}} \frac{\bar{y}_{r}^{b}}{y_{r 0}^{b}}\right)} \\
& \text { s.t. } \sum_{j=1, \neq 0}^{n} x_{j} \lambda_{j} \leq \bar{x} ; \sum_{j=1, \neq 0}^{n} y_{j}^{g} \lambda_{j} \geq \bar{y}^{g} ; \sum_{j=1, \neq 0}^{n} y_{j}^{b} \lambda_{j} \geq \bar{y}^{b} ; \\
& \bar{x} \geq x_{0}, \bar{y}^{g} \leq y_{0}^{g}, \bar{y}^{b} \leq y_{0}^{b}, \bar{y}^{g} \geq 0, \lambda \geq 0 .
\end{aligned}
$$

where $\rho_{\text {se }}$ denotes the value of super-efficiency, $x, y, b$ denote input, desirable output, and undesirable output, respectively. If and only if $\rho_{\text {se }} \geq 1$, the DMU is regarded as DEA efficient; otherwise, the DMU is regards as DEA inefficient.

\subsection{Malmquist-Luenberger index}

The eco-efficiency measured by super-efficiency SBM-DEA or traditional DEA model is analyzed from a static perspective, which fails to describe the dynamic changes in totalfactor ecological productivity. In order to analyze the changes, the Malmquist productivity index was initially proposed in 1953 by Malmquist (1953). Then, Caves et al. (1982) and Färe et al. (1994) developed the method based on distance function, which has been a popular tool for measuring productivity.

However, the productivity of the companies that face environmental regulations may be affected by the cost for pollution treatment (Chung et al. 1997). Thus, the 
Malmquist-Luenberger (M-L) index considering undesirable outputs was proposed by Chung et al. (1997). As shown in Eq. (2), the Malmquist-Luenberger index can be further decomposed into technological change and efficiency change.

$$
\begin{aligned}
\mathrm{M}-\mathrm{L} & =\left[\frac{D_{c}^{t}\left(x^{t+1}, y^{t+1}, b^{t+1}\right)}{D_{c}^{t}\left(x^{t}, y^{t}, b^{t}\right)} \times \frac{D_{c}^{t+1}\left(x^{t+1}, y^{t+1}, b^{t+1}\right)}{D_{c}^{t+1} 1\left(x^{t}, y^{t}, b^{t}\right)}\right]^{1 / 2} \\
& =\frac{D_{c}^{t}\left(x^{t+1}, y^{t+1}, b^{t+1}\right)}{D_{c}^{t}\left(x^{t}, y^{t}, b^{t}\right)} \times\left[\frac{D_{c}^{t}\left(x^{t+1}, y^{t+1}, b^{t+1}\right)}{D_{c}^{t+1}\left(x^{t+1}, y^{t+1}, b^{t+1}\right)} \times \frac{D_{c}^{t}\left(x^{t}, y^{t}, b^{t}\right)}{D_{c}^{t+1} 1\left(x^{t}, y^{t}, b^{t}\right)}\right]^{1 / 2} \\
& =T C \times E C
\end{aligned}
$$

where $\left(x^{t}, y^{t}, b^{t}\right)$ and $\left(x^{t+1}, y^{t+1}, b^{t+1}\right)$ denote input, desirable output and undesirable output at period $t$ and $t+1$, respectively. $D_{c}^{t}$ and $D_{c}^{t+1}$ denote the distance functions based on inputs and outputs at period $t$ for the production technology at $t$ and $t+1$, respectively. $T C$ denotes technological change, $E C$ denotes efficiency change. If the $\mathrm{M}-\mathrm{L}$ index is greater than 1 , it indicates that the productivity level of the city has increased from $t$ to $t+1$. If the $\mathrm{M}-\mathrm{L}$ index is less than 1, it indicates that the productivity level of the city has fallen down from $\mathrm{t}$ to $t+1$.

\subsection{Overall human well-being index}

Generally speaking, human well-being mainly includes two aspects: (1) The objective aspect or objective well-being; (2) The subjective aspect or subjective well-being. In fact, two aspects of human well-being are interplayed, and the subjective aspect is determined by the objective aspect. To a certain extent, the objective aspect of well-being is primary in relation to the subjective aspect, but it is not the part of or the basis of the subjective aspect (Alatartseva and Barysheva 2015). Specifically, the objective well-being is measured by quantitative indicators characterized by the level and stability of income, the conditions of residence, the opportunity of having education, which reflect the degrees to which human needs are met. HDI, proposed and promoted by the United Nations Development Program (UNDP) since 1990, has been widely employed as a proxy of objective well-being, which aims to measure the socio-economic development of states or regions including three dimensions such as a decent standard of living, long and health life, and education (Zhang et al. 2018). The subjective well-being is conceptualized as an internal subjective experience of each particular individual, being less material, less tangible, less quantitative, and more subjective (Alatartseva and Barysheva 2015). Subjective well-being is respondents' self-assessed satisfaction with and cognitive evaluations of their lives (Cavalletti and Corsi, 2018; Markussen et al. 2014). Subjective well-being is accepted and used as an appropriate and reliable measure of human well-being due to its directness (Binder et al. 2020; Maccagnan et al. 2019). Life satisfaction is one frequently used indictor of subjective wellbeing (Zhang and Zhu 2020).

With regards to well-being at the city level, urban residents' satisfaction is an important metric in evaluating cities, as efforts to improve city performance ultimately affect the benefit and comfort of urban residents (Nakamura and Managi 2020). Although objective indicators indicate significant differences among residents in cities, subjective perceptions may not be different (Veenhoven 1996). Therefore, objective indicators may differ from subjective indicators. For a better and comprehensive assessment, the overall human well-being 
index is proposed in this paper, which is constituted by both objective well-being and subjective well-being indicators. The details of the calculation process are as below:

Firstly, the urban HDI (UHDI), as the objective well-being indicator at city level, is calculated in accordance with the UNDP standard adopted in 2010 (UNDP 2010).

$$
\mathrm{UHDI}=\sqrt[3]{\mathrm{LEI} \times \mathrm{YEI} \times \mathrm{EI}}
$$

where UHDI denotes Human Development Index (HDI) at the city level, LEI denotes life expectance at birth, YEI denotes education, EI denotes economic income. All the indicators are converted into index value with zero dimension.

Secondly, due to the data availability, life satisfaction is selected as a proxy indicator of subjective well-being in this study, which is obtained directly from the Report on the Quality of Life in Chinese Cities.

Then, for the convenience of calculation, the overall human well-being index is measured by urban HDI and life satisfaction of urban residents as below equation.

$$
\mathrm{OWBI}=\mathrm{UHDI} \times 0.5+\mathrm{SWBI} \times 0.5
$$

where OWBI denotes the overall level of well-being, UHDI denotes urban residents' objective well-being, SWBI denotes subjective well-being index. For the convenience of comparison, both UHDI and SWBI enjoy a same weight of 0.5 .

\subsection{Variables and data}

This study covers 35 major cities in China, which are provincial capital or sub-provincial cities that enjoy high representativeness and availability of data. Lasa is excluded due to the data availability. As for the study period, since the indicators of statistical system, method of survey, and related technologies were revised by the former Ministry of Environmental Protection in 2011, and the statistical scope has been revised. In addition, the latest data of environment and related are only available by 2015 . Thus, the study period is set from 2011 to 2015, which is the 12th Five-Year Plan period (2011-2015) as well. To measure total-factor eco-efficiency comprehensively, all of the input and output variables should be considered to the extent that the data are available. Thus, we choose 35 major cities as DMUs; capital, labor, land, energy and water as inputs; GDP as a desirable output; and $\mathrm{SO}_{2}$ emission as an undesirable output. The capital input is measured by capital stock, and the capital stock is estimated by the perpetual inventory method (Qin et al. 2017) with the data of total investment fixed assets of each city. All the original data were obtained from the China City Statistical Yearbook (2012-2016), the China Statistical Yearbook on Environment (2012-2016), the China Urban Construction Statistical Yearbook (2011-2015), the Statistical Communiqué on the National Economic and Social Development (2011-2015) and the Water Resources and Environmental Bulletin (2011-2015) of each city.

Considering the availability of data and on the basis of the related studies on eco-efficiency (Wang and Yang 2019; Xing et al. 2018; Yan et al. 2018), labor input is measured by the total number of employees at the end of each year, land input is measured by urban built-up areas, energy input is measured by energy intensity (energy consumed per unit of GDP) of each city and it is converted to standard coal, water input is measured by total water consumption, and Choose GDP as the ideal output. As for undesirable output, $\mathrm{SO}_{2}$ emission is adopted as a proxy, as it is commonly used as the pollutants when measuring eco-efficiency, and it has been widely used as an undesirable output by many scholars (Golany et al. 1994; Färe et al. 2005; Burnett and Hansen 2008; Alfredsson et al. 2016). 
Data of urban residents' life satisfaction can be obtained directly from the Report on the Quality of Life in Chinese Cities (2012-2016), which is annually issued by the Quality of Urban Life Research Center since 2011, by 2017, the Research Center has conducted its QLICC survey on 35 Chinese major cities for 7 years. Thus, the data of life satisfaction enjoy high representativeness and reference value. It is worth nothing that the data of $\mathrm{SO}_{2}$ emission are obtained from both industry and household source in this study, since the household pollutants have become a big threaten to the urban ecosystem along with the rapid urbanization, and all monetary related variables such as GDP and capital stock are converted into 2010 constant price with GDP deflators to eliminate the price effect.

\section{Results and discussion}

In this section, the total-factor eco-efficiency efficiency of 35 major cities in China from 2011 to 2015 is measured by the improved super-efficiency SBM-DEA model considering undesirable output under the assumption of constant returns to scale (CRS), and the dynamic analysis on TFP is conducted by Malmquist-Luenberger index. Then, effectiveness measured by overall human well-being index of each cities is described, and a comprehensive analysis is carried out based on efficiency and effectiveness.

\subsection{Measurement and evaluation of eco-efficiency}

Figure 1 shows the ranking of eco-efficiency of 35 major cities in China. Cities and three regions are ranked by their mean values of eco-efficiency. According to Fig. 1, we can see obviously that the top five cities are Shenzhen, Changsha, Qingdao, Changchun and Beijing, while the bottom five cities are Kunming, Chongqing, Guiyang, Lanzhou and Yinchuan. According to Table 1, the empirical results indicate that the overall efficiency as a whole is at a low level, only seven cities are eco-efficient, while the rest of the 28 cities are eco-inefficient. Specifically speaking, Shenzhen, Changsha, Qingdao, Changchun, Beijing, and Ningbo are efficient in a single year throughout the 12th Five-Year Plan period (2011-2015). Tianjin could be considered as efficient in terms of its mean value of eco-efficiency. Dalian, Shenyang, Hangzhou, Fuzhou, Hohhot, Jinan, Zhengzhou, Wuhan,

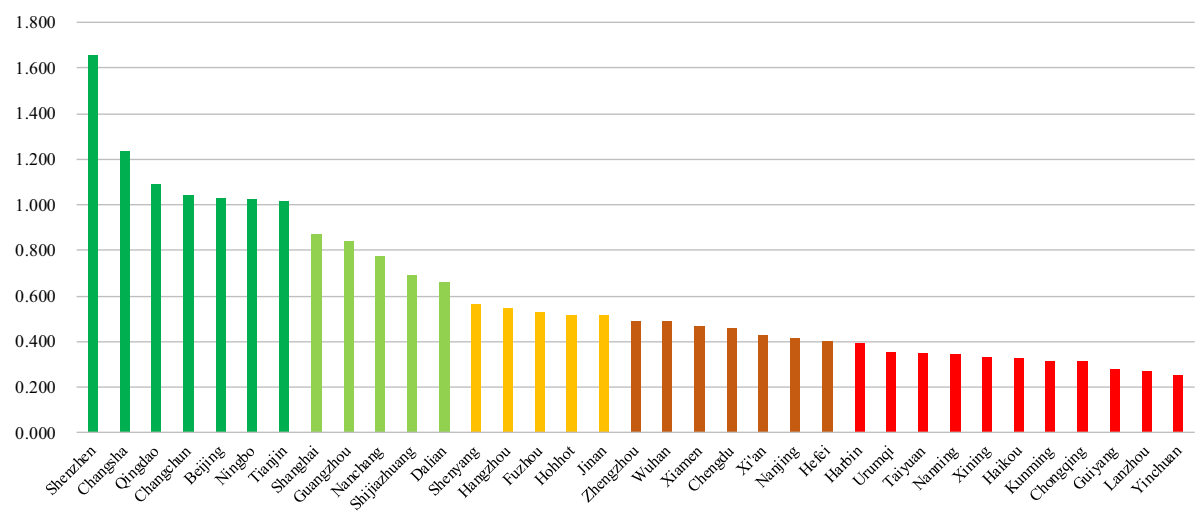

Fig. 1 Ranking of total-factor eco-efficiency of 35 cities in China during the period 2011-2015 
Table 1 Total-factor eco-efficiency of 35 major cities in China from 2011 to 2015

\begin{tabular}{|c|c|c|c|c|c|c|c|c|}
\hline Region & City & 2011 & 2012 & 2013 & 2014 & 2015 & Mean & Rank \\
\hline \multirow[t]{16}{*}{ Eastern Region } & Beijing & 1.025 & 1.024 & 1.023 & 1.023 & 1.030 & 1.025 & 5 \\
\hline & Tianjin & 0.722 & 1.003 & 1.081 & 1.152 & 1.105 & 1.013 & 7 \\
\hline & Shijiazhuang & 1.021 & 1.001 & 0.484 & 0.461 & 0.472 & 0.688 & 11 \\
\hline & Shenyang & 0.618 & 0.628 & 0.551 & 0.523 & 0.501 & 0.564 & 13 \\
\hline & Shanghai & 1.076 & 1.069 & 1.018 & 0.623 & 0.582 & 0.874 & 8 \\
\hline & Nanjing & 0.448 & 0.440 & 0.412 & 0.384 & 0.377 & 0.412 & 23 \\
\hline & Hangzhou & 0.587 & 0.540 & 0.547 & 0.533 & 0.524 & 0.546 & 14 \\
\hline & Fuzhou & 0.569 & 0.523 & 0.527 & 0.521 & 0.516 & 0.531 & 15 \\
\hline & Jinan & 0.497 & 0.501 & 0.529 & 0.528 & 0.537 & 0.518 & 17 \\
\hline & Guangzhou & 0.550 & 0.595 & 1.020 & 1.022 & 1.017 & 0.841 & 9 \\
\hline & Haikou & 0.367 & 0.341 & 0.325 & 0.300 & 0.282 & 0.323 & 30 \\
\hline & Dalian & 0.586 & 0.622 & 0.690 & 0.644 & 0.749 & 0.658 & 12 \\
\hline & Qingdao & 1.157 & 1.109 & 1.048 & 1.026 & 1.084 & 1.085 & 3 \\
\hline & Ningbo & 1.009 & 1.020 & 1.034 & 1.016 & 1.014 & 1.018 & 6 \\
\hline & Xiamen & 0.485 & 0.481 & 0.476 & 0.464 & 0.447 & 0.470 & 20 \\
\hline & Shenzhen & 1.578 & 1.587 & 1.655 & 1.678 & 1.780 & 1.656 & 1 \\
\hline \multirow[t]{8}{*}{ Central Region } & Taiyuan & 0.359 & 0.343 & 0.376 & 0.328 & 0.321 & 0.346 & 27 \\
\hline & Changchun & 1.048 & 1.058 & 1.035 & 1.042 & 1.011 & 1.039 & 4 \\
\hline & Harbin & 0.369 & 0.353 & 0.411 & 0.403 & 0.405 & 0.388 & 25 \\
\hline & Hefei & 0.407 & 0.406 & 0.401 & 0.411 & 0.395 & 0.404 & 24 \\
\hline & Nanchang & 0.421 & 0.431 & 1.008 & 1.004 & 1.011 & 0.775 & 10 \\
\hline & Zhengzhou & 0.485 & 0.468 & 0.498 & 0.503 & 0.493 & 0.489 & 18 \\
\hline & Wuhan & 0.423 & 0.453 & 0.525 & 0.525 & 0.512 & 0.487 & 19 \\
\hline & Changsha & 1.146 & 1.215 & 1.256 & 1.271 & 1.267 & 1.231 & 2 \\
\hline \multirow[t]{11}{*}{ Western Region } & Chengdu & 0.533 & 0.469 & 0.424 & 0.467 & 0.397 & 0.458 & 21 \\
\hline & Chongqing & 0.326 & 0.292 & 0.316 & 0.309 & 0.308 & 0.310 & 32 \\
\hline & Guiyang & 0.287 & 0.272 & 0.264 & 0.273 & 0.297 & 0.279 & 33 \\
\hline & Kunming & 0.317 & 0.305 & 0.278 & 0.310 & 0.346 & 0.311 & 31 \\
\hline & Xi'an & 0.431 & 0.425 & 0.435 & 0.426 & 0.411 & 0.426 & 22 \\
\hline & Lanzhou & 0.265 & 0.278 & 0.283 & 0.272 & 0.259 & 0.271 & 34 \\
\hline & Xining & 0.321 & 0.316 & 0.335 & 0.341 & 0.351 & 0.333 & 29 \\
\hline & Yinchuan & 0.284 & 0.267 & 0.279 & 0.226 & 0.218 & 0.255 & 35 \\
\hline & Urumqi & 0.339 & 0.362 & 0.418 & 0.324 & 0.330 & 0.355 & 26 \\
\hline & Nanning & 0.325 & 0.377 & 0.353 & 0.340 & 0.325 & 0.344 & 28 \\
\hline & Hohhot & 0.501 & 0.528 & 0.525 & 0.525 & 0.513 & 0.518 & 16 \\
\hline National average & & 0.597 & 0.603 & 0.624 & 0.606 & 0.605 & 0.607 & - \\
\hline Eastern Region & & 0.768 & 0.780 & 0.776 & 0.744 & 0.751 & 0.764 & 1 \\
\hline Central Region & & 0.582 & 0.591 & 0.689 & 0.686 & 0.677 & 0.645 & 2 \\
\hline Western Region & & 0.357 & 0.354 & 0.355 & 0.347 & 0.341 & 0.351 & 3 \\
\hline
\end{tabular}

Xiamen, Chengdu, Xi'an, Nanjing, Hefei, Harbin, Urumqi, Taiyuan, Nanning, Xining, Haikou, Kunming, Chongqing, Guiyang, Lanzhou, Yinchuan are inefficient during these 5 years. Shijiazhuang is only efficient in the first two years (2011-2012), Shanghai is only 
efficient in the first three years (2011-2013), then turn to inefficiency in following years, Guangzhou and Nanchang are only efficient in the last three years (2012-2015), Shanghai and Shijiazhuang have seen a sudden change from efficient to inefficient, while Guangzhou and Nanchang have witnessed a significant improvement of eco-efficiency. From a regional perspective, as shown in Table 2, the ranking shows a trend that Eastern Region at the top, Central Region in the second, and Western Region at the bottom. In addition, we can find that there is a big gap between Western Region and the other two regions in terms of eco-efficiency.

\subsection{Total-factor ecological productivity}

The above results of eco-efficiency measured by super-efficiency SBM-DEA model considering undesirable output are mainly for static analysis. In order to further explore the change trend of total-factor ecological productivity, the Malmquist-Luenberger (M-L) index is measured by Eq. (2) over the time of 2011-2015. The M-L indexes of 35 cities are shown in Table 2.

According to Table 2, we can find that the M-L index of urban eco-efficiency as a whole is greater than 1 during the study period. The $\mathrm{M}-\mathrm{L}$ index of 2011-2012, 2012-2013, 2013-2014, 2014-2015 is greater than 1. Among them, the M-L index in period of 2011-2012 improves 12.9\%, being the highest score. Furthermore, both the mean value of technological change index and efficiency change index are greater than 1 , while the mean value of technological change index is higher than that of efficiency

Table 2 Malmquist-Luenberger index of 35 major cities in China during 2011-2015

\begin{tabular}{llllllllll}
\hline City & EC & TC & M-L & Rank & City & EC & TC & M-L & Rank \\
\hline Beijing & 1.001 & 1.012 & 1.013 & 31 & Nanchang & 1.341 & 1.128 & 1.469 & 1 \\
Tianjin & 1.123 & 1.032 & 1.159 & 8 & Zhengzhou & 1.005 & 1.067 & 1.071 & 17 \\
Shijiazhuang & 0.860 & 1.457 & 1.166 & 7 & Wuhan & 1.051 & 1.072 & 1.125 & 9 \\
Shenyang & 0.950 & 1.153 & 1.100 & 10 & Changsha & 1.026 & 1.020 & 1.046 & 21 \\
Shanghai & 0.873 & 1.179 & 0.998 & 34 & Chengdu & 0.934 & 1.114 & 1.040 & 24 \\
Nanjing & 0.958 & 1.072 & 1.028 & 28 & Chongqing & 0.988 & 1.053 & 1.039 & 25 \\
Hangzhou & 0.973 & 1.380 & 1.338 & 3 & Guiyang & 1.010 & 1.047 & 1.059 & 19 \\
Fuzhou & 0.977 & 1.463 & 1.428 & 2 & Kunming & 1.026 & 1.054 & 1.083 & 13 \\
Jinan & 1.020 & 1.069 & 1.089 & 11 & Xi'an & 0.988 & 1.063 & 1.049 & 20 \\
Guangzhou & 1.198 & 1.045 & 1.234 & 5 & Lanzhou & 0.995 & 1.046 & 1.040 & 23 \\
Haikou & 0.936 & 1.079 & 1.010 & 32 & Xining & 1.023 & 1.054 & 1.077 & 15 \\
Dalian & 1.067 & 1.153 & 1.227 & 6 & Yinchuan & 0.940 & 1.045 & 0.980 & 35 \\
Qingdao & 0.985 & 1.033 & 1.016 & 30 & Urumqi & 1.004 & 1.038 & 1.034 & 27 \\
Ningbo & 1.001 & 1.083 & 1.084 & 12 & Nanning & 1.004 & 1.060 & 1.066 & 18 \\
Xiamen & 0.980 & 1.064 & 1.042 & 22 & Hohhot & 1.006 & 1.238 & 1.249 & 4 \\
Shenzhen & 1.031 & 1.008 & 1.039 & 26 & $2011-2012$ & 1.006 & 1.124 & 1.129 & 1 \\
Taiyuan & 0.976 & 1.049 & 1.021 & 29 & $2012-2013$ & 1.060 & 1.055 & 1.095 & 2 \\
Changchun & 0.991 & 1.018 & 1.009 & 33 & $2013-2014$ & 0.969 & 1.134 & 1.095 & 3 \\
Harbin & 1.027 & 1.049 & 1.075 & 16 & $2014-2015$ & 0.995 & 1.097 & 1.091 & 4 \\
Hefei & 0.993 & 1.087 & 1.080 & 14 & Mean & 1.007 & 1.102 & 1.102 & - \\
\hline & & & & & & & &
\end{tabular}


change index. Two indexes are greater than 1, which indicates that both the efficiency change and technological progress play positive effects on eco-efficiency, while the improvement of eco-efficiency is mainly contributed by technological improvement.

At the city level, from Table 2, among 35 major cities in China, the total-factor productivity indexes of 9 cities are above the national average, while the indexes of other 26 cities are under the national average. The top five cities are Nanchang, Fuzhou, Hangzhou, Hohhot and Guangzhou. While the bottom five cities are: Beijing, Haikou, Changchun, Shanghai, and Yinchuan. With regarding to the efficiency change, 18 cities including Beijing, Tianjin, Jinan, Guangzhou, Dalian, Ningbo, Shenzhen, Harbin, Nanchang, Zhengzhou, Wuhan, Changsha, Guiyang, Kunming, Xining, Urumqi, Nanning and Hohhot are greater than 1, the rest of 17 cities including Shijiazhuang, Shenyang, Shanghai, Nanjing, Hangzhou, Fuzhou, Haikou, Qingdao, Xiamen, Taiyuan, Changchun, Hefei, Chengdu, Chongqing, Xi'an, Lanzhou, Yinchuan are less than 1, which indicates it fails to play a positive role in eco-efficiency, and more efforts should be made to reduce energy consumption and environmental pollutions.

At the regional level, as shown in Fig. 2, the mean values of M-L index of urban eco-efficiency in three regions are greater than 1 . The improvement of eco-efficiency in Eastern Region is mainly contributed by technological progress change, which indicates that the industrial upgrading of Eastern Region has been effectively completed by technological progress. While the mean value of the efficiency change index is less than 1 , which indicates that the scale effects in the Eastern Region is on the decreasing trend, high-quality industrial development will contribute to the improvement of eco-efficiency. In the Central Region, the total-factor eco-efficiency is also mainly affected by technological progress, and the efficiency change index of Central Region is higher than Eastern Region, which indicates that the scale economy of the western region played a positive role during the study period. In the Western Region, the efficiency change index is less than 1, which indicates more efforts should be made to reduce energy consumption and pollutants emission.

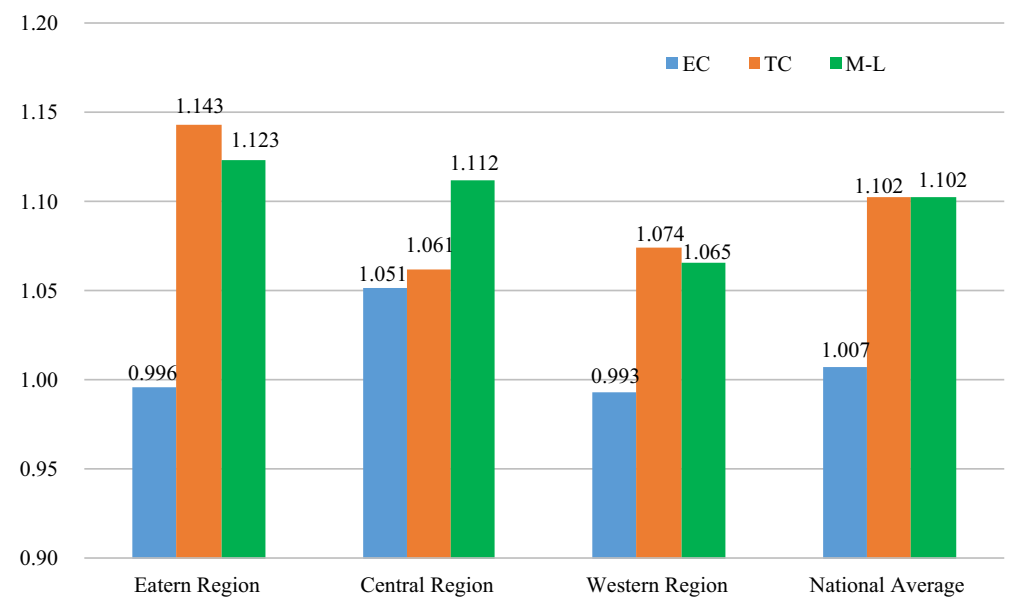

Fig. 2 Mean of M-L index of three regions and national average 


\subsection{Effectiveness: Urban HDI and life satisfaction}

Figure 3 shows the results and rankings of over human well-being index (OWBI), HDI and subjective well-being (SWB) of 35 major cities in China during 2011-2015.

Considering the over human well-being of each city, according to Fig. 3, we can see that Hangzhou, Jinan, Ningbo, Xiamen, and Qingdao rank top five, while Kunming, Shenzhen, Nanjing, Lanzhou and Guiyang rank bottom five. Due to a relatively low level of life satisfaction, mega cities like Guangzhou, Shanghai, and Beijing with high-level economic development and urban HDI only rank in the middle.

As for the objective well-being, as shown in Fig. 3, we can see the ranking of urban HDI of 35 major cities in China during the period of 2011-2015. According to Fig. 3, we can see that Guangzhou, Shanghai, Beijing ranks in the top three in turn in terms of urban HDI, while Chongqing, Xining, and Guiyang ranks in the bottom three. We can also find that there's a huge gap among the 35 cities in China, more attention should be paid to narrow the gap between Eastern Region and Western Region.

As for the subjective well-being, we choose life satisfaction as the proxy, according to Fig. 3, an interesting phenomenon is found that the life satisfaction is not linearly correlated with the urban HDI. Although Guangzhou, Shanghai, Beijing, Dalian, and Tianjin ranks top 5 in terms of urban HDI, the life satisfaction is at a relatively low level, especially Beijing, which means the urban residents from those five big cities, seems to be unsatisfied with the urban environment, or feel unhappy to some extent.

\subsection{Comprehensive analysis based on efficiency and effectiveness}

Sustainable urban development not only focuses on the ecological efficiency, but also the effectiveness. Specifically speaking, the ecological efficiency emphasizes sustained economic growth with minimized resource depletion and environmental pollution, and the effectiveness emphasizes a high level of overall well-being characterized by decent income, long and healthy life, high level of education, and being happy in or satisfied with their life, which is the ultimate goal of sustainable development. Thus, efficiency and effectiveness are the key two aspects for evaluating urban sustainability.

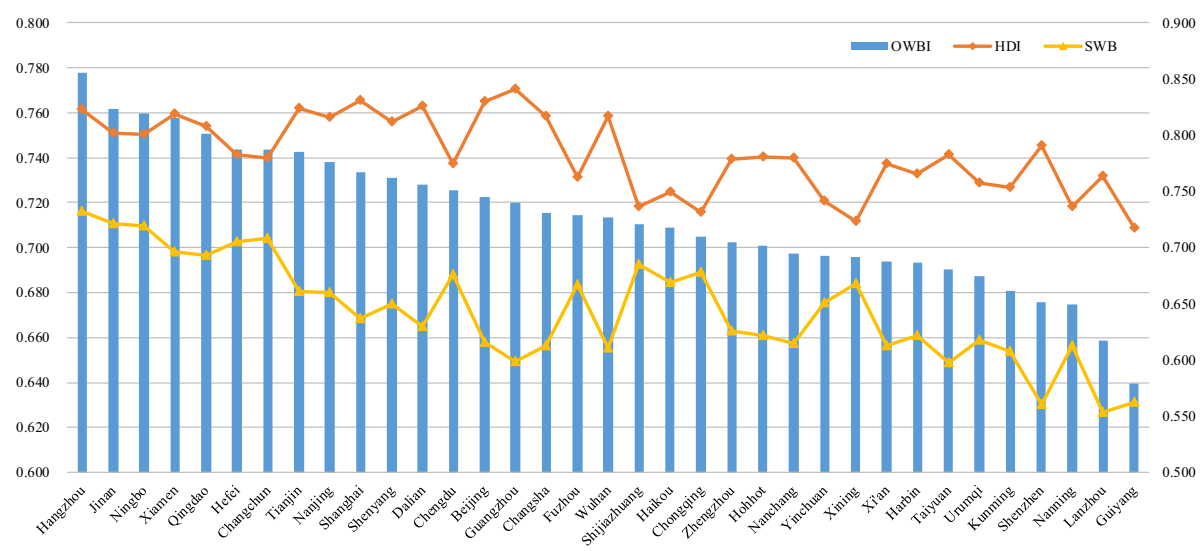

Fig. 3 Rankings of OWBI, urban HDI and subject well-being (2011-2015) 
As shown in Fig. 4, 35 cities are classified into four types based on the eco-efficiency measured by Super-efficiency SBM-DEA model and the effectiveness measured by the overall human well-being index. According to the DEA method, only when the value of eco-efficiency is greater than or equals to 1 can be considered as DEA efficient, then the city will be regarded as high efficiency accordingly; otherwise, the city will be considered inefficient. For the effectiveness evaluation, as there is no unified standard to judge the overall well-being index, we define the overall well-being index in the top 10 that are greater than 0.734 as high-level well-being, then the development of the city will be regarded as good effectiveness; otherwise, the city will be considered inefficient. In this way, four types include as follows:

(1) High efficiency and High effectiveness (H-H): Four cities including Qingdao, Changchun, Ningbo, and Tianjin perform highly efficient and effective, which are the models of sustainable urban development for other 31 cities.

(2) Low efficiency and High effectiveness (L-H): Seven cities including Hangzhou, Shanghai, Nanjing, Hefei, Xiamen, Jinan, and Shenyang perform highly effective with a low efficiency, which means the cities are in the right way of development with a high ecological input. Thus, more attention should be paid to improve eco-efficiency, especially reduce resource consumption and environmental pollution.

(3) Low efficiency and Low effectiveness (L-L): 21 cities including Guangzhou, Dalian, Chengdu, Nanchang, Wuhan, Fuzhou, Shijiazhuang, Zhengzhou, Chongqing, Haikou, Xi' an, Hohhot, Taiyuan, Harbin, Nanning, Guiyang, Kunming, Xining, Yinchuan, Lanzhou and Urumqi perform eco-inefficiently with poor effectiveness. For Guangzhou, Dalian, Chengdu, these three cities are close to high effectiveness, and the ecoefficiency of Guangzhou and Nanchang is close to 1 . Some other cities, especially the cities like Lanzhou, Yinchuan, etc., in the Western Region perform inefficiently along

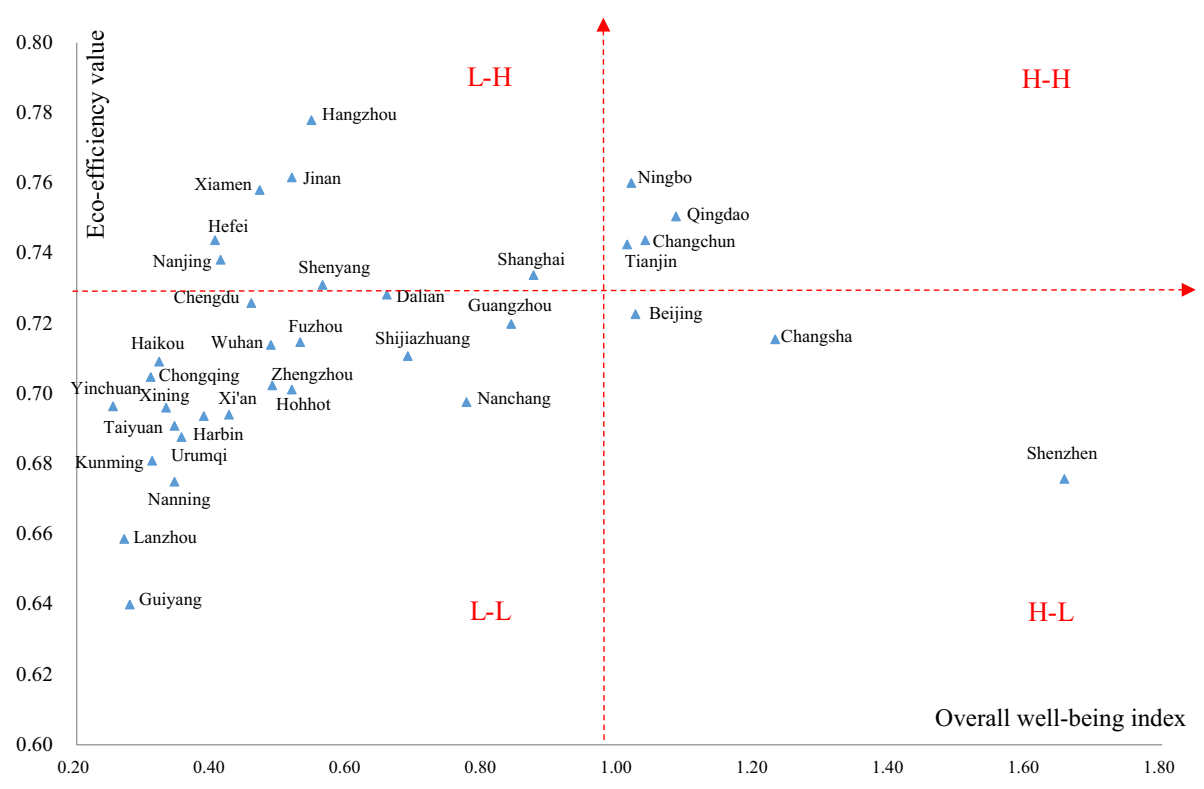

Fig. 4 Two-dimensional matrix analysis based on efficiency and effectiveness 
with a very low level of urban human development, in which both eco-efficiency and HDI should be improved to a large extent.

(4) High efficiency and Low effectiveness (H-L): Three cities including Beijing, Shenzhen, and Changsha perform high efficiently but with low or poor effectiveness, which indicates that all these three cites need to improve overall well-being. For Beijing, the objective well-being is at a high level in terms of urban HDI according to Fig. 3, which ranks in the third place, but the level of subjective well-being is not high, caused by the fog haze weather occurred frequently in Beijing in recent years, more efforts should be focused on the life satisfaction improvement. For Shenzhen, both urban HDI and life satisfaction should be improved, especially the life satisfaction is at a very low level, which may be related to a high pressure or cost of living in Shenzhen.

\section{Conclusions and policy implications}

In this paper, the efficiency and effectiveness are considered to evaluate sustainable urban development of 35 major cities in China during the period 2011-2015. Firstly, the efficiency of sustainable urban development is measured, i.e., measuring the eco-efficiency of 35 major cities in China during the period of 2011-2015 based on a super-efficiency SBM-DEA model in which capital, labor, land, energy, and water are adopted as inputs, and gross domestic product (GDP) is considered as a desirable output and $\mathrm{SO}_{2}$ emission is treated as an undesirable output, and the Malmquist-Luenberger index is introduced to explore the dynamic change of total-factor eco-efficiency. Secondly, the effectiveness of urban development is measured by overall well-being including urban HDI and life satisfaction. Thirdly, a comprehensive analysis based on efficiency and effectiveness is conducted to evaluate sustainable urban development. Some major findings based on the empirical results are concluded as follows:

(1) The overall efficiency of 35 major cities in China as a whole is at a low level during the 12th Five-Year Plan period (2011-2015), only seven cities are eco-efficient. From a regional perspective, the Eastern Region ranks at the top, Central Region in the second, and Western Region at the bottom. The improvement of total-factor ecological productivity is mainly enhanced by technological progress, while efficiency change promotes the productivity in the first two periods and the recent two periods have been hindering productivity growth.

(2) With regarding to the effectiveness of urban development, Hangzhou, Jinan, Ningbo, Xiamen, and Qingdao rank top five in terms of overall well-being index, while the cities with a high level of urban HDI like Guangzhou, Changsha, and Beijing only rank in the middle due to a relatively low level of life satisfaction.

(3) Based on efficiency and effectiveness, most of the cities perform with a low-level efficiency or poor effectiveness, only four cities including Qingdao, Changchun, Ningbo, and Tianjin perform with high-level efficiency and good effectiveness, which indicates that more efforts should be made by the local government in China to improve ecoefficiency or well-being including urban HDI or life satisfaction.

Based on the above empirical results, some implications and policy suggestions are proposed as follows: 
(1) Improvements on efficiency or effectiveness are varied from different cities. The cities with a high level of economic development and urban HDI like Shanghai, Guangzhou, and Hangzhou should pay more attention on the reduction of resource consumption such as water use to improve eco-efficiency. For the cities with a high level of economic development and urban HDI like Beijing and Shenzhen, more efforts should be made to improve life satisfaction. While the cities with a low level of efficiency and poor effectiveness, especially the western cities like Lanzhou and Yinchuan, more attention should be paid to increase economic growth to improve the education and medical conditions within the eco-capacity.

(2) Since technological progress is found to be the main driving force to improve ecological productivity growth in three regions, especially in the western region. More efforts should be made to introduce advanced technology and technological innovation, and strengthen cooperation and exchanges between cities and regions. In addition, it is urgently to develop green eco-industry instead of the industry with high energy consumption and heavy pollution.

(3) Local governments should attach equal importance to efficiency and effectiveness to promote sustainable urban development, rather than GDP-oriented development. A sustainable city should provide high-level human well-being including urban HDI and life satisfaction with high-level eco-efficiency. Since eco-efficiency emphasizes less resource depletion and environmental pollution during the process of economic growth, while effectiveness emphasizes the ultimate goal of sustainable urban development, that is to sustained high-level human well-being. GDP is one way to improve human well-being, but not the ultimate goal of urban development.

Open Access This article is licensed under a Creative Commons Attribution 4.0 International License, which permits use, sharing, adaptation, distribution and reproduction in any medium or format, as long as you give appropriate credit to the original author(s) and the source, provide a link to the Creative Commons licence, and indicate if changes were made. The images or other third party material in this article are included in the article's Creative Commons licence, unless indicated otherwise in a credit line to the material. If material is not included in the article's Creative Commons licence and your intended use is not permitted by statutory regulation or exceeds the permitted use, you will need to obtain permission directly from the copyright holder. To view a copy of this licence, visit http://creativecommons.org/licenses/by/4.0/.

\section{References}

Alatartseva, E., \& Barysheva, G. A. (2015). Well-being: Subjective and objective aspects. Procedia Social and Behavioral Sciences, 166, 36-42.

Alfredsson, E., Månsson, J., \& Vikström, P. (2016). Internalising external environmental effects in efficiency analysis: The Swedish pulp and paper industry 2000-2007. Economic Analysis and Policy, 51, 22-31.

Banker, R. D., Charnes, A., \& Cooper, W. W. (1984). Some models for estimating technical and scale inefficiencies in data envelopment analysis. Management Science, 30(9), 1078-1092.

Binder, M., Blankenberg, A.-K., \& Guardiola, J. (2020). Does it have to be a sacrifice? Different notions of the good life, pro-environmental behavior and their heterogeneous impact on well-being. Ecological Economics, 167, 106448.

Böhringer, C., \& Jochem, P. E. P. (2007). Measuring the immeasurable: A survey of sustainability indices. Ecological Economics, 63(1), 1-8.

Boone, C. G., \& Fragkias, M. (2013). Urbanization and sustainability. In Linking urban ecology, environmental justice and global environmental change.

Brundtland, G. H., \& Khalid, M. (1987). Our common future. In Earth and Us Population-Resources-Environment-Development (pp. 29-31). 
Burnett, R. D., \& Hansen, D. R. (2008). Ecoefficiency: Defining a role for environmental cost management. Accounting Organizations and Society, 33(6), 551-581.

Cavalletti, B., \& Corsi, M. (2018). "Beyond GDP" effects on national subjective well-being of OECD countries. Social Indicators Research, 136(3), 931-966.

Caves, D. W., Christensen, L. R., \& Diewert, W. (1982). The economic theory of index numbers and the measurement of input, output, and productivity. Econometrica, 50(6), 1393-1414.

Charnes, A. A., Cooper, W. W., \& Rhodes, E. (1978). Measuring the efficiency of decision making units. European Journal of Operational Research, 2(6), 429-444.

Chung, Y. H., Färe, R., \& Grosskopf, S. (1997). Productivity and undesirable outputs: A directional distance function approach. Journal of Environmental Management, 51(3), 229-240.

Cook, W. D., \& Seiford, L. M. (2009). Data envelopment analysis (DEA)-Thirty years on. European Journal of Operational Research, 192(1), 1-17.

Cooper, W. W., Seiford, L. M., \& Tone, K. (2006). Introduction to data envelopment analysis and its uses: With DEA-solver software and references (2nd ed.). Boston: Springer Science \& Business Media.

Dresner, S. (2012). The principles of sustainability. London: Routledge.

Färe, R., Grosskopf, S., Noh, D.-W., \& Weber, W. (2005). Characteristics of a polluting technology: Theory and practice. Journal of Econometrics, 126(2), 469-492.

Färe, R., Grosskopf, S., Norris, M., \& Zhang, Z. (1994). Productivity growth, technical progress, and efficiency change in industrialized countries. The American Economic Review, 84(1), 66-83.

Golany, B., Roll, Y., \& Rybak, D. (1994). Measuring efficiency of power plants in Israel by data envelopment analysis. IEEE Transactions on Engineering Management, 41(3), 291-301.

Ikeda, S., \& Managi, S. (2019). Future inclusive wealth and human well-being in regional Japan: Projections of sustainability indices based on shared socioeconomic pathways. Sustainability Science, 14(1), 147-158.

Lin, J., Li, Y., Wang, W., Cui, S., \& Wei, X. (2010). An eco-efficiency-based urban sustainability assessment method and its application. International Journal of Sustainable Development and World Ecology, 17(4), 356-361.

Maccagnan, A., Wren-Lewis, S., Brown, H., \& Taylor, T. (2019). Wellbeing and society: Towards quantification of the co-benefits of wellbeing. Social Indicators Research, 141(1), 217-243.

Malmquist, S. (1953). Index numbers and indifference surfaces. Trabajos De Estadistica, 4(2), $209-242$.

Mardani, A., Zavadskas, E. K., Streimikiene, D., Jusoh, A., \& Khoshnoudi, M. (2017). A comprehensive review of data envelopment analysis (DEA) approach in energy efficiency. Renewable \& Sustainable Energy Reviews, 70, 1298-1322.

Marks, N., Abdallah, S., Simms, A., \& Thompson, S. (2006). The happy planet index. London: New Economics Foundation. Available at http://www.happyplanetindex.org.

Markussen, T., Fibæk, M., Tarp, F., \& Tuan, N. D. A. (2014). The Happy Farmer: Self-employment and subjective well-being in rural Vietnam. Journal of Happiness Studies, 19(6), 1613-1636.

Moussiopoulos, N., Achillas, C., Vlachokostas, C., Spyridi, D., \& Nikolaou, K. (2010). Environmental, social and economic information management for the evaluation of sustainability in urban areas: A system of indicators for Thessaloniki, Greece. Cities, 27(5), 377-384.

Nakamura, H., \& Managi, S. (2020). Effects of subjective and objective city evaluation on life satisfaction in Japan. Journal of Cleaner Production, 256, 120523.

National Bureau of Statistics of China (NBSC). (2020). Statistical Bulletin on National Economic and Social Development in 2019. Available at http://www.stats.gov.cn/tjsj/zxfb/202002/t2020 0228_1728913.html.

Bloomberg News. (2012). China's urban population exceeds rural dwellers for first time in history. A6. Seattle Times, January 18.

Opschoor, H. (2011). Local sustainable development and carbon neutrality in cities in developing and emerging countries. International Journal of Sustainable Development and World Ecology, 18(3), 190-200.

Qin, Q., Li, X., Li, L., Zhen, W., \& Wei, Y. M. (2017). Air emissions perspective on energy efficiency: An empirical analysis of China's coastal areas. Applied Energy, 185, 604-614.

Schaltegger, S., \& Sturm, A. (1990). "Environmental Rationality" (in German: Ökologische Rationalität). Die Unternehmung, Nr., 4, 117-131.

Shaw, D. J. (1991). Human development report, 1990. Futures, 23(1), 102-104.

Shen, L.-Y., Ochoa, J. J., Shah, M. N., \& Zhang, X. (2011). The application of urban sustainability indicators-A comparison between various practices. Habitat International, 35(1), 17-29.

Singh, R. K., Murty, H. R., Gupta, S. K., \& Dikshit, A. K. (2009). An overview of sustainability assessment methodologies. Ecological Indicators, 15(1), 281-299. 
Tone, K. (2001). A slacks-based measure of super-efficiency in data envelopment analysis. European Journal of Operational Research, 130(3), 498-509.

Tone, K. (2002). A slacks-based measure of efficiency in data envelopment analysis. European Journal of Operational Research, 143(1), 32-41.

Veenhoven, R. (1996). Developments in satisfaction research. Social Indicators Research, 37(1), 1-46.

Wackernagel, M., \& Rees, W. (1996). Our ecological footprint: Reducing human impact on the earth. Gabriola Island: New Society Publishers.

Wang, H., \& Yang, J. (2019). Total-factor industrial eco-efficiency and its influencing factors in China: A spatial panel data approach. Journal of Cleaner Production, 227, 263-271.

Wursthorn, S., Poganietz, W.-R., \& Schebek, L. (2011). Economic-environmental monitoring indicators for European countries: A disaggregated sector-based approach for monitoring eco-efficiency. Ecological Economics, 70(3), 487-496.

Xing, Z., Wang, J., \& Zhang, J. (2018). Total-factor ecological efficiency and productivity in Yangtze River Economic Belt, China: A non-parametric distance function approach. Journal of Cleaner Production, 200, 844-857.

Yan, Y., Wang, C., Quan, Y., Wu, G., \& Zhao, J. (2018). Urban sustainable development efficiency towards the balance between nature and human well-being: Connotation, measurement, and assessment. Journal of Cleaner Production, 178, 67-75.

Yang, D. (2012). Spatial logic and risks of China's rapid urbanization under global complexity. City Planning Review, 11, 83-91.

Yin, K., Wang, R., An, Q., Yao, L., \& Liang, J. (2014). Using eco-efficiency as an indicator for sustainable urban development: A case study of Chinese provincial capital cities. Ecological Indicators, 36(1), 665-671.

Yue, S., Yang, Y., \& Pu, Z. (2017). Total-factor ecology efficiency of regions in China. Ecological Indicators, 73, 284-292.

Zhang, D., Lei, L., Ji, Q., \& Kutan, A. M. (2019). Economic policy uncertainty in the US and China and their impact on the global markets. Economic Modelling, 79, 47-56.

Zhang, S., \& Zhu, D. (2020). Have countries moved towards sustainable development or not? Definition, criteria, indicators and empirical analysis. Journal of Cleaner Production, 267, 121929.

Zhang, S., Zhu, D., Shi, Q., \& Cheng, M. (2018). Which countries are more ecologically efficient in improving human well-being? An application of the Index of Ecological Well-being Performance. Resources Conservation and Recycling, 129, 112-119.

Publisher's Note Springer Nature remains neutral with regard to jurisdictional claims in published maps and institutional affiliations. 